\title{
Ethical dilemmas in COVID-19 times: how to decide who lives and who dies?
}

\author{
Nedy M. B. C. Neves ${ }^{1}$ \\ Flávia B. C. S. N. Bitencourt ${ }^{2}$ \\ (DD) Almir G. V. Bitencourt ${ }^{3}$
}

1. Universidade Salvador (Unifacs), Salvador, BA, Brasil 2. Fleury Medicina e Saúde, São Paulo, SP, Brasil 3. A.C.Camargo Cancer Center, São Paulo, SP, Brasil

http://dx.doi.org/10.1590/1806-9282.66.S2.106

\section{SUMMARY}

The respiratory disease caused by the coronavirus SARS-CoV-2 (COVID-19) is a pandemic that produces a large number of simultaneous patients with severe symptoms and in need of special hospital care, overloading the infrastructure of health services. All of these demands generate the need to ration equipment and interventions. Faced with this imbalance, how, when, and who decides, there is the impact of the stressful systems of professionals who are at the front line of care and, in the background, issues inherent to human subjectivity. Along this path, the idea of using artificial intelligence algorithms to replace health professionals in the decision-making process also arises. In this context, there is the ethical question of how to manage the demands produced by the pandemic. The objective of this work is to reflect, from the point of view of medical ethics, on the basic principles of the choices made by the health teams, during the COVID-19 pandemic, whose resources are scarce and decisions cause anguish and restlessness. The ethical values for the rationing of health resources in an epidemic must converge to some proposals based on fundamental values such as maximizing the benefits produced by scarce resources, treating people equally, promoting and recommending instrumental values, giving priority to critical situations. Naturally, different judgments will occur in different circumstances, but transparency is essential to ensure public trust. In this way, it is possible to develop prioritization guidelines using well-defined values and ethical recommendations to achieve fair resource allocation.

KEYWORDS: Ethics, Medical. Bioethics. Pandemics. Coronavirus Infections. Decision Making. Resource Allocation.

\section{INTRODUCTION}

The respiratory disease caused by the Coronavirus 2019 (COVID-19) is a pandemic with serious clinical manifestations, including death, and affecting countries on all continents. The coronavirus type 2 was the virus that caused severe acute respiratory syndrome (Sars-Cov-2), a disease responsible for the infection of millions of individuals and hundreds of thousands of deaths worldwide'.

Due to its high transmissibility, COVID-19 produces a simultaneous large number of patients with severe symptoms that require special hospital care, overloading the infrastructure of health services ${ }^{2}$. It has been demonstrated that no health system in the world is capable of managing all these patients if a large portion of the population is contaminated. The number of deaths in some countries has shocked the world and unveiled one of the biggest problems generated by the pandemic. The crisis due to the number of patients who require special care and hospitalizations, the resulting volume of equipment and multidisciplinary 
teams needed, all in discrepancy with the scarcity of such equipment, thus collapsing the health system.

All these demands made it necessary to ration equipment and interventions. The imbalance between supply and demand of resources leads to the question of how these resources can be allocated fairly ${ }^{2}$. As a consequence of this imbalance, there is the matter of how to, when to, and who will make such decisions, and, in addition to the underlying and inherent issues of human subjectivity, professionals who are at the frontline of care already have to cope with the impact of stressful systems. Thus arises the idea of using artificial intelligence (AI) algorithms to replace health professionals in this decision-making ${ }^{3-5}$.

Considering the aspects mentioned and taking into account the crisis promoted by the discrepancy between the number of patients and the diagnostic and therapeutic tools of medical assistance, the questioning remains on how to manage the demands produced by the pandemic. The objective of this study is to reflect, from the point of view of medical ethics, on the basic principles of the choices made by health teams in the fight against the COVID-19 pandemic, dealing with scarce resources and having to make decisions that cause anguish and anxiety.

\section{MEDICAL CARE NETWORK}

In view of the facts mentioned in the introduction, it is worth reflecting on the scenario of the healthcare structures for critical patients who, consequently, require special equipment. These conditions are not related only to patients with positive results for COVID-19, but to any citizen whose pathology can weaken the health system, with a life-threatening risk. In this context, some authors have reported that the problem of hospital infrastructure with limited access is old and remains true in many regions. Goldwasser et al. ${ }^{6}$, for example, relate a small number of units and demand, which generates a gap between availability and the admission flow. In short, the authors have reported that the system defends universal care, but there is no room for everyone.

The ICUs are key components in the care of patients with an imminent risk of death and chance of recovery ${ }^{6}$. Due to its high degree of complexity, ICUs are a costly resource in hospital units, corresponding to approximately $20 \%$ of the operational costs ${ }^{7}$. Given this, there is a reduced number of ICUs, which do not service everyone who needs them, thus rejecting patients and generating queues for hospitalizations. There is a gap between availability and the demand for ICU beds. In addition to the inadequate infrastructure, there is also an absence of protocols and a lack of trained human resources ${ }^{6-8}$.

In isolation, some strategies have been developed to minimize these difficulties through regulatory policies that aim to organize the admission to services and procedures of high and medium complexity. A central manages the demands and resources available to provide the best care at an appropriate time. The regulation is based on technical criteria of priorities, following hierarchical protocols, based on a consensus by specialized medical societies, and prioritizing the most severe patients 9 .

The planning of healthcare services is a complex social problem and requires multidisciplinary approaches. The organization of these systems is influenced by technical, epidemiological, ethical, educational, and cultural aspects. In order to substantiate the decision making that permeates medical conflicts, oftentimes it is mandatory to consult with and seek guidance from the institution's Ethics Committee $^{10}$. All these arguments show that the ICU resources, with the necessary equipment for critical and serious health situations, are in deficit regardless of pandemics.

\section{RATIONALIZATION OF CARE}

How to make choices when there are numerous demands and lack of resources? Sartre ${ }^{11}$ argues that: "Man is condemned to be free." To Sartre ${ }^{11}$, our preferences are guided by what appears to be good, more specifically by an engagement in which represents good. Considering this scenario, the current question includes the approaches to allocate scarce resources. It is necessary to prepare to make tragic decisions, such as who lives and who dies. A utilitarian and pragmatic perspective would defend allocating resources to those with the greatest chance of survival and a greater time of remaining life. It is rationality based on cost-benefit that can have or not an ethical value.

Conversely, there are principles that propose saving as many lives as possible and ensuring no economic, racial, ethnic, or political bias. In this line of reasoning, it is not acceptable that financial conditions and social status are considered criteria of choice. Faced with this scenario, let's look at an example: a young 20-year-old man and a 60-year-old patient, 
both with comparable forecasts, who would be given the benefit? Who will be saved? This and other challenges are in the hands of doctors at the frontline of emergency care. Faced with the anguish of this type of decision, it is believed that the task of allocating resources fairly could be shared with mechanisms that can minimize this overload of physicians.

\section{MEDICAL AND TEAM CONFLICT}

It is scientific knowledge that doctors work under pressure from their families, colleagues, and hospital managers to decide which patient will be benefited from the use of the ICU. In addition, the concept of priority varies based on individual judgment, interpretation, social responsibility, and transparency. Physicians who are in charge of the care of severe patients, deciding when and how the first support measures must be initiated, timely, are oftentimes young and unprepared. Considering this, it is essential to broaden the training of professionals ${ }^{6}$. Therefore, it is noted that the responsibility of deciding priorities is born by a single professional, the physician, with their human subjectivity and with risks of mistakes and successes. It is clear that these facts generate anguish and suffering in professionals.

There is no consensus in the literature of any scientific area; therefore, in some circumstances, the experience of a certain professional can guide the diagnostic and therapeutic determination, despite going against scientific evidence. Sometimes the best strategy is directly related to the experience of each service. Empiricism appears as a solution when it is acknowledged that the routine approach does not contemplate a routine situation ${ }^{12}$.

An important milestone in the medical area was "evidence-based medicine". This pattern was built based on a mental process that evidences clinical reasoning, including the calculation of probabilities of outcomes, risks, and benefits in such a way that becomes relevant for the establishment of scientific evidence. This emerges as a tendency to replace subjectivity by technical objectivity. Following a new paradigm, protocols were created based on scientific studies in order to standardize the practice and make it safer to benefit patients and physicians alike ${ }^{12}$. In view of these facts, there are authors who advocate the introduction of protocols in medical practice, while others consider intersubjectivity restrictive to the construction of objective decisions as support of scientificity ${ }^{13}$.
One must consider that all of these mechanisms were devised for the good of the patient; however, physicians risk becoming a "robot" that only follows frameworks and protocols without getting involved in the search for the best scientifically recognized solution at their disposal.

\section{MODELING OF THE COVID-19 PANDEMIC}

There are demonstrative data available to project the demands of resources. Estimates of the reproduction number of Sars-Cov-2 show that each infected person spreads the virus to at least two other, on average. Of all the patients infected with COVID-19, approximately $15 \%$ have severe diseases, and $5 \%$ have critical needs. The overall mortality ranges from $0.25 \%$ to $3.0 \%$. Mortality is higher in vulnerable populations, such as people over 80 years old $(>14 \%)$ and with comorbidities, $10 \%$ for patients with heart disease, and $7 \%$ for diabetics. Several factors, such as social distancing and other interventions can influence the calculation of the total population infected; however, the estimate is around $5 \%{ }^{14}$.

The model of scarcity previously observed extends to diagnostic, therapeutic, and preventive interventions $^{2}$. Pharmaceutical products and experimental treatments are in the early stages of study ${ }^{15}$. In the same way, a vaccine will take time to be developed, produced, and distributed. Based on the foregoing, is it possible to predict that the time necessary to achieve the goals that can balance the system imposed by the pandemic is still long, requiring a structuring and making, therefore, the prognosis bleak.

\section{AI IN PROBLEM SOLVING}

AI can interfere and help in the creation of standards and protocols to assist physicians in making the previously mentioned choices in the face of severe patients in a critical situation. Currently, AI covers a huge variety of subfields. Among these is the study of connective models or neural networks (CNN, convolutional neural networks). A neural network can be seen as a simplified mathematical model of the functioning of the human brain ${ }^{16}$.

One of the areas most studied by scientists about $\mathrm{AI}$ is the process of Problem Solving, which was developed by analyzing the behaviors of individuals who solve problems to simulate aspects of intelligent and rational behavior. The AI planning techniques have 
allowed the generation of a plan that solved a problem in a few hours, something that would take other methods weeks to achieve. Among the software created are those for medical diagnosis based on probabilistic analysis, and they were able to execute tasks at the same level as a doctor who specializes in various areas of medicine. In this same line, the literature presents proposals for replacing causal, mechanistic, or structural clinical reasoning models for models of determining probabilistic that are typical of epidemiological reasoning ${ }^{17.18}$. These mechanisms include the assumptions of their knowledge pool and concepts of practical nature through methods and tools used in the examination of evidence and criteria to assess its results ${ }^{12}$.

Therefore, is it possible to join strengths to develop effective and faster systems to reduce the shortage observed and, thus, fight the problems faced in this pandemic crisis ${ }^{19}$.

\section{ETHICAL VALUATION}

From an ethical perspective, it can be argued that value judgment is an attempt of judgment based on a careful evaluation of the information available, taken as incomplete and evolving. It is worth exemplifying a value judgment on how to proceed in a medical emergency. In this case, the quality of judgment is incomplete since it is the result of cultural or personal limitations. Valuation is essential as an element for the contextualization of ethics in its broadest sense. Ethics is shaped based on the ingraining of values in subjects and the society in which they are inserted, and, from this set, each one proposes their actions ${ }^{20}$. That being said, it is necessary to valuate to intervene. It is worth noting that the medical field assigns a different value to life, according to age, providing distinct care to children, adults, and the elderly ${ }^{12}$.

From this perspective, the ethical values necessary to ration healthcare resources in an epidemic have high prestige and can converge into some proposals based on fundamental values, such as maximizing the benefits produced by scarce resources, treating people equitably, promoting and recommending instrumental values, and giving priority to critical situations ${ }^{21}$. A recently published article taking into account the ethical particularities mentioned produced specific recommendations to allocate medical resources in the COVID-19 pandemic ${ }^{2}$ :

1. Maximize benefits - the priority of limited resources should aim at saving as many lives as possible and maximizing improvements throughout life post-treatment. This premise is consistent both in the perspective of utilitarian and non-utilitarian ethics.

2. Prioritize health professionals - resources such as tests, PPE, ICU beds, ventilators, therapeutics, and vaccines should be directed initially to healthcare professionals, particularly those who face a high risk of infection and whose training makes them difficult to replace, which can cause insufficient assistance and, as a result, an increased number of deaths due to the decreased number of trained professionals.

3. Do not allocate based on the order of arrival - in case of patients with a similar prognosis, the operationalization should be random. Prioritizing those who arrived first would be unfair.

4. Be sensitive to the scientific evidence - protocols must follow scientific guidelines and be updated as they develop.

5. Reward research participants - people who participate in research to prove the safety and effectiveness of vaccines and therapeutic measures should receive some priority in interventions.

6. Apply the same principles to all COVID-19 and non-COVID-19 patients - the fair allocation of resources that prioritizes the value of maximizing benefits applies to all patients who need them.

It is necessary to implement policies of rationing in order to balance multiple ethical values. Naturally, there will be different judgments in different circumstances, but it is essential to maintain transparency to ensure public trust ${ }^{2}$. It is possible to draw up prioritization guidelines using well-established ethical values and recommendations to achieve fair procedures for resource allocation. That way, it is possible to prevent individual physicians from being faced with the grim task of improvising decisions.

\section{FINAL CONSIDERATIONS}

Certainly, there is much to be said about this topic; therefore, there are no pretensions of exhausting it here, given that in the history of humanity the evolution of thought is a historically recognized reality. In other words, problems are not impervious and solutions are changeable.

Despite what has been studied and seeking to achieve the objective proposed, many are the possibilities to contribute to the efforts of minimizing the dilemma of medical teams in circumstances of 
a scarcity of resources in which they are coerced to make tragic decisions. In this aspect, it is worth reinforcing the six aforementioned recommendations that can ensure that physicians do not have to handle the task of deciding alone and can still count on a higher level of problem-solving in the organizational sphere the institution, relieving their emotional burden. In addition to that, there is the guarantee of equal treatment when patients are at the same level of prognosis, in the search for the equity of access to resources, something which must be considered in each case.

The defense of the creation of broad and well-defined scientific protocols to assist teams in making difficult decisions is advocated by several authors as one of the ways of distancing physicians at the frontline, from the responsibility of an inappropriate choice. There is validity in institutions creating models and parameters that can employ screening professionals, physicians who are not allocated to direct patient care, and medical committees specialized in ethics to apply guidelines that may help in making the decisions around the rationing and implementation of definitive choices. In this scenario, AI can assist in the generation of a multitude of probabilistic sets for hypothetical problems, comparing them with the similarity of the real problems, and from these events, cooperate for a more appropriate choice. In this same line of argument, governments have the legitimate right to draw up public policies that might hinder the scarcity of medical resources, such as ICU beds, respirators, monitors, and infusion pumps, in addition to PPE and testing for healthcare professionals who are at the frontline, preventing the risk of contamination. Therefore, AI algorithms can also be useful as an auxiliary tool to streamline inventory control, the standardization of purchases of raw materials, transport, and logistics.

The downside is that even well-designed guidelines can present challenging problems in decision-making. In other words, a well-defined protocol does not guarantee its applicability, nor its suitability of use. In addition, an excess of protocols and routines homogenize practices, and professionals start adopting intuitive and pragmatic approaches. Finally, a key point is the use of AI as an auxiliary strategy of this praxis. Given the above, it is possible to reframe healthcare through the work of teams composed of multiple players, even AI. This process aims to reduce problems while solutions are researched and answer questions to avoid anguish and suffering.

\section{Author's Contribution}

All authors contributed to the concept of the theme of the work, literature review, drafting, and revising the manuscript.

\section{RESUMO}

A doença respiratória provocada pelo coronavírus 2019 (COVID-19) é uma pandemia que produz uma grande quantidade simultânea de doentes com sintomas graves que necessitam de cuidados hospitalares especiais, sobrecarregando a infraestrutura dos serviços de saúde. Todas essas demandas geram a necessidade de racionar equipamentos e intervenções. Diante desse desequilíbrio, como, quando e quem decide, há o impacto dos sistemas estressores dos profissionais que se encontram na linha de frente do atendimento e, em segundo plano, questões inerentes à subjetividade humana. Nesse percurso, surge ainda a ideia do uso de algoritmos da inteligência artificial para substituir o profissional de saúde nessa tomada de decisão. Nesse contexto, fica o questionamento ético de como gerenciar as demandas produzidas pela pandemia. O objetivo deste trabalho é refletir, do ponto de vista da ética médica, sobre princípios basilares das escolhas executadas pelas equipes de saúde, no enfrentamento da pandemia da COVID-19, cujos recursos são escassos e as decisões ocasionam angústia e inquietação. Os valores éticos para o racionamento de recursos de saúde em uma epidemia devem convergir para algumas propostas embasadas em valores fundamentais, como maximizar os benefícios produzidos por recursos escassos, tratar as pessoas de forma igualitária, promover e recomendar os valores instrumentais, dar prioridade para situações críticas. Naturalmente ocorrerão julgamentos diferentes em circunstâncias distintas, mas é fundamental que haja transparência para garantir a confiança pública. Desse modo, é possivel elaborar diretrizes de priorização utilizando valores e recomendações éticas bem delineados para atingir procedimentos justos de alocação de recursos.

PALAVRAS-ChaVe: Ética médica. Bioética. Pandemias. Infecções por coronavírus. Tomada de decisões. Alocação de recursos.

\section{REFERENCES}

1. Cespedes MS, Souza JCRP. Coronavirus: a clinical update of COVID-19. Rev Assoc Med Bras. 2020;66(2):116-23.

2. Emanuel EJ, Persad G, Upshur R, Thome B, Parker M, Glickman A, et al. Fair allocation of scarce medical resources in the time of COVID-19. N Engl Med. 2020;382(21):2049-55.
3. Jiang X, Coffee M, Bari A, Wang J, Jiang X, Huang J, et al. Towards an artificial intelligence framework for data-driven prediction of coronavirus clinical severity. CMC. 2020;63(1):537-51.

4. Yan L, Zhang H-T, Xiao Y, Wang M, Sun C, Liang J, et al. Prediction of criticality in patients with severe COVID-19 infection using three clinical features: 
a machine learning-based prognostic model with clinical data in Wuhan. medRxiv 2020;2020.02.27.20028027. doi: https://doi.org/10.1101/2020.02 .27 .20028027

5. Naudé W. Artificial intelligence vs COVID-19: limitations, constraints and pitfalls. Al Soc. 2020;1-5. doi: 10.1007/s00146-020-00978-0.

6. Goldwasser RS, Lobo MSC, Arruda EF, Angelo SA, Ribeiro ECO, Silva IRLE. Planning and understanding the intensive care network in the State of Rio de Janeiro (RJ), Brasil: a complex societal problem. Rev Bras Ter Intensiva. 2018;30(3):347-57.

7. Rivers E, Nguyen B, Havstad S, Ressler |, Muzzin A, Knoblich B, et al; Early Goal-Directed Therapy Collaborative Group. Early goal-directed therapy in the treatment of severe sepsis and septic shock. N Engl J Med. 2001;345(19):1368-77.

8. Halpern NA, Pastores SM. Critical care medicine in the United States 2000-2005: an analysis of bed numbers, occupancy rates, payer mix, and costs. Crit Care Med. 2010;38(1):65-71.

9. Bloomfield EL. The ethics of rationing of critical care services: should technology assessment play a role? Anesthesiol Res Pract. 2009;2009:915197.

10. Vecina Neto G, Malik AM. Tendências na assistência hospitalar. Cienc Saúde Coletiva. 2007;12(4):825-39.

11. Sartre J. O existencialismo é um humanismo. Petrópolis: Editora Vozes; 2014.

12. Uchôa SAC, Camargo Jr KR. Os protocolos e a decisão médica: medicina baseada em vivências e ou evidências? Cienc Saúde Coletiva. 2010;15(4):2241-9.

13. Eddy DM. Clinical decision making: from theory to practice. Resolving conflicts in practice policies. JAMA. 1990;264(3):389-91.

14. Wu Z, McGoogan JM. Characteristics of and important lessons from the coronavirus disease 2019 (COVID-19) outbreak in China: Summary of a report of 72314 cases from the Chinese Center for Disease Control and Prevention. JAMA. 2020. doi: 10.1001/jama.2020.2648.

15. Harrison C. Coronavirus puts drug repurposing on the fast track. Nat Biotechnol. 2020;38(4):379-81.

16. Osaki MM. Inteligência artificial, prática médica e a relação médico-paciente. Rev Adm Saúde. 2018;18(72). http://dx.doi.org/10.23973/ras.72.134.

17. Beil M, Proft I, van Heerden D, Sviri S, van Heerden PV. Ethical considerations about artificial intelligence for prognostication in intensive care. Intensive Care Med Exp. 2019;7(1):70.

18. Kang DY, Cho KJ, Kwon O, Kwon JM, Jeon KH, Park H, et al. Artificial intelligence algorithm to predict the need for critical care in prehospital emergency medical services. Scand I Trauma Resusc Emerg Med. 2020;28(1):17.

19. lenca $M$, Vayena $E$. On the responsible use of digital data to tackle the COVID-19 pandemic. Nat Med. 2020;26(4):463-4.

20. Neves NC. Ética para os futuros médicos. É possível ensinar? Brasília: Conselho Federal de Medicina; 2006.

21. Persad G, Wertheimer A, Emanuel El. Principles for allocation of scarce medical interventions. Lancet. 2009;373(9661):423-31. 